\title{
Article \\ A Computationally Efficient Model Predictive Control of Six-Phase Induction Machines Based on Deadbeat Control
}

\author{
João Serra (D), Imed Jlassi * (D) and Antonio J. Marques Cardoso $\mathbb{D}$ \\ CISE-Electromechatronic Systems Research Centre, University of Beira Interior, Calçada Fonte do Lameiro, \\ P-6201-001 Covilhã, Portugal; joao.serra@ubi.pt (J.S.); ajmcardoso@ieee.org (A.J.M.C.) \\ * Correspondence: jlassi-imed@hotmail.fr
}

check for updates

Citation: Serra, J.; Jlassi, I.; Cardoso, A.J.M. A Computationally Efficient Model Predictive Control of Six-Phase Induction Machines Based on Deadbeat Control. Machines 2021, 9, 306. https://doi.org/10.3390/ machines9120306

Academic Editor: Dan Zhang

Received: 19 October 2021

Accepted: 20 November 2021

Published: 23 November 2021

Publisher's Note: MDPI stays neutral with regard to jurisdictional claims in published maps and institutional affiliations.

Copyright: (c) 2021 by the authors. Licensee MDPI, Basel, Switzerland. This article is an open access article distributed under the terms and conditions of the Creative Commons Attribution (CC BY) license (https:/ / creativecommons.org/licenses/by/ $4.0 /)$.

\begin{abstract}
Model predictive current control (MPCC) has recently become a viable alternative for multiphase electric drives, because it easily exploits the inherent advantages of multi-phase machines. However, the prediction in MPCC requires a high number of voltage vectors (VVs), being therefore computationally demanding. In that regard, this paper proposes a computationally efficient MPCC of an asymmetrical six-phase induction machine drive (ASIMD) that reduces the number of VVs used for prediction. By using the characteristics of the deadbeat control (DB), the proposed method obtains a reference voltage vector (RVV), where its position will serve as a reference and integrates the MPCC scheme. Only 4 out of 13 predictions are needed to determine the best VV, dramatically reducing the algorithm computation. Experimental results for a six-phase case study compare the standard MPCC with the suggested method, confirming that deadbeat model predictive current control (DB-MPCC) shows that the execution time can be shortened by $48.8 \%$ and successfully improve the motor performance and efficiency.
\end{abstract}

Keywords: model predictive current control; deadbeat control; execution time; asymmetrical sixphase induction machine drive

\section{Introduction}

In recent years, multiphase machines drives have received a great deal of attention from the power electronics community due to their good features, such as fault-tolerant capability, low current per phase, high torque density, etc. [1]. Multiphase machines have been widely applied in industries, especially for high power and high-reliability industry applications such as ultra-high-speed elevators [2], electric ship propulsion [3], and wind power generation [4]. On the other hand, model predictive control (MPC) of electrical drives has gained an impressive amount of attention. MPC became the main competitor to field oriented control (FOC) and direct torque control (DTC) due to its inherent advantages: straight-forward concept, the ability to easily include multiple nonlinear constraints into the optimization problem, and excellent control dynamics [5]. Recent contributions on MPC have been proposed to control electrical systems [6-15], to diagnose the fault in power converters [16-19], to ensure the post-fault operation of fault-tolerant systems [20,21], or to assess the impact of mismatch parameters [22].

The majority of the control approaches applied to multiphase drives are commonly an extension of the control techniques applied to three-phase drives. In classical MPC, stator currents, torque, and stator flux, as the controlled variables, are predicted from the mathematical model of the machine with all available finite voltage vectors (VVs). By minimizing the error between the reference value and the predicted values, the best VV can be obtained. Although advantageous, MPC demands a high computational burden due to all VVs combinations being used for prediction and evaluation [10]. Accordingly, with the increase in the complexity of the converter, the amount of feasible VVs increases and, therefore, the computation effort rises. Furthermore, with high sampling times, large current ripples are produced, decreasing the overall drive efficiency. Moreover, very fast 
and expensive digital processors are required. However, the acceptance by the industry will be low if their implementation cannot be accomplished in a cost-effective way.

An $m$-level $n$-phase inverter has $m^{n}$ space VVs so, a six-phase two-level voltage source inverter (2L-VSI) has $2^{6}$ which means 64 different space VVs, corresponding to the switching states. Of those $64 \mathrm{VVs}, 48$ include active VVs, 12 are redundant and 4 are null VVs. The VVs can be grouped into four distinct categories, according to their magnitude. The 48 active VVs can be mapped into $\alpha-\beta$ and $x-y$ subspaces, applying the vector space decomposition (VSD) technique. The $\alpha-\beta$ subspace is responsible for the torque ripple production and for the harmonics of the order $12 n \pm 1(n=1,2,3, \ldots)$. On the other hand, $x$-y does not contribute to the air-gap flux and torque production, and it includes all the supply harmonics of the order $6 n \pm 1(n=1,3,5, \ldots)$.

The use of MPC was introduced to dual three-phase electric drives in [23]. The work proved that penalizing the current harmonic in the cost function reduces greatly the harmonic content of the current. With the issue of high computation time, several predictive schemes were proposed to avoid the excessive computational burden. Some studies $[24,25]$ developed predictive schemes based on virtual voltage vectors (VVVs). The VVs of the $\alpha-\beta$ subspace and the $x-y$ subspace were combined, simplifying the two spaces into one that only contains 13 VVVs. However, the amplitude of the VVVs is constant, meaning that serious harmonics would be generated when the amplitude of back electromotive force (back-EMF) does not match the one of the VVVs.

Another way to simplify the optimization problem is to directly obtain a reference voltage vector (RVV) based on deadbeat control (DB). DB can be based on deadbeat direct torque and flux control (DB-DTFC) [26], or deadbeat model predictive current control (DB-MPCC) $[27,28]$. The controlled variables for the different approaches of DB, such as stator currents or torque and stator flux, are predicted from the mathematical model of the machine in order to obtain the RVV, which will select the closer optimal VV. The DB-DTFC is more accurate in controlling the torque and flux, when compared to DB-MPCC. The cost function is also defined in the form of the error between the absolute value of the RVV and the feasible VVs, which is different from the model predictive current control (MPCC) or model predictive torque control (MPTC).

In $[29,30]$, the DB is employed on six-phase permanent magnet synchronous machine (PMSM) to reduce the number of VVs, by estimating an RVV. In the $\alpha-\beta$ subspace, 12 regions can be defined, within which the RVV can be found. The region where the RVV is, defines the VVs employed on the cost function. In [29], for each region, $2 \mathrm{VVs}$ aligned, are selected along with a null VV. In [30] 3 aligned VVs and a null VV are chosen. However, poor control can be achieved, due to the use of only two or three active VVs from each region, especially at the region extremities.

In classical MPCC for asymmetrical six-phase induction machine drive (ASIMD), evaluating all the $49 \mathrm{VVs}$ is redundant since the computing time is a crucial factor for MPCC implementation. A common practice consists of only evaluating 13 VVs (12 large active VVs and 1 null VV) [23,29,30]. Unfortunately, evaluating $13 \mathrm{VVs}$ is still significant.

However, to the authors' knowledge, a less computationally demanding MPCC based on DB, applied to an ASIMD, which aims to obtain superior control performance, has not yet been reported in the literature. Motivated by the aforementioned drawback, this paper intends to simultaneously reduce the high computation effort and enhance the control performance. The proposed method allows the regulation of the $x-y$ currents, ensuring a reduction in the stator copper losses and promoting drive efficiency. The proposed DBMPCC has as principle the DB, where the RVV is obtained. The position of the RVV gives a region in $\alpha-\beta$ subspace, and according to its location, the feasible VVs are selected. In each region there is one distinct large VV. Then, the two closest large VVs are also involved in the cost function with 1 null VV to avoid poor control in the region extremities and to improve the control performance. Accordingly, in each sampling time four VVs are selected, to be evaluated by the cost function. The optimal VV is then selected and applied during the next sampling period. As a result, the number of required VVs is effectively reduced from 
13 possible VVs to $4 \mathrm{VVs}$; consequently, a low computational time is achieved, allowing for shorter sampling time and further enhancing the control performance. The proposed control algorithm is tested and validated by intensive experimental results.

\section{System Model}

The analyzed system consists of an ASIMD with isolated neutral points, fed by a sixphase 2L-VSI and a DC voltage source. A simplified scheme of the implemented topology is shown in Figure 1.

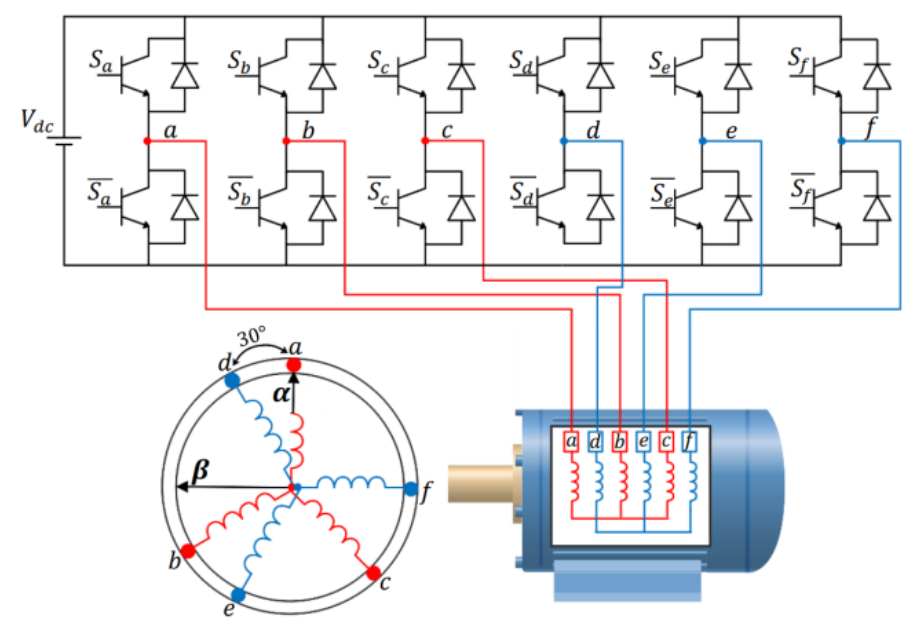

Figure 1. General scheme of an ASIMD controlled by a six-phase 2L-VSI.

\subsection{Voltage Source Inverters}

The switching state of each VSI leg is defined as $S_{i} \in\{0,1\}$, where if $S_{i}=1$, the upper switch of the leg $i$ is ON and the lower switch of the same leg is OFF, and if $S_{i}=0$ the opposite occurs. It is then possible to group the switching states of the VSI as a VV $[S]=\left[S_{a} S_{b} S_{c} S_{d} S_{e} S_{f}\right]$, which provides $2^{6}=64$ possible different combinations of VVs. Each stator phase voltage can be obtained through the $64 \mathrm{VVs}$, which can, in turn, be mapped into the $\alpha-\beta, x-y$ and $0^{+}-0^{-}$subspaces according to the VSD approach in (1):

$$
\left[T_{v s d}\right]=\frac{1}{3}\left[\begin{array}{cccccc}
1 & -\frac{1}{2} & -\frac{1}{2} & \frac{\sqrt{3}}{2} & -\frac{\sqrt{3}}{2} & 0 \\
0 & \frac{\sqrt{3}}{2} & -\frac{\sqrt{3}}{2} & \frac{1}{2} & \frac{1}{2} & -1 \\
1 & -\frac{1}{2} & -\frac{1}{2} & -\frac{\sqrt{3}}{2} & \frac{\sqrt{3}}{2} & 0 \\
0 & -\frac{\sqrt{3}}{2} & \frac{\sqrt{3}}{2} & \frac{1}{2} & \frac{1}{2} & -1 \\
1 & 1 & 1 & 0 & 0 & 0 \\
0 & 0 & 0 & 1 & 1 & 1
\end{array}\right]
$$

The $\alpha-\beta$ subspace is the pair responsible for the electromechanical energy conversion, representing the fundamental supply component plus supply harmonics of the order $12 n \pm 1(n=1,2,3, \ldots)$. The second pair, $x-y$ subspace, does not contribute to the air-gap flux and torque and it includes all the supply harmonics of the order $6 n \pm 1(n=1,3,5, \ldots)$. The third pair, $0^{+}-0^{-}$subspace, corresponds to the zero sequence harmonic components. These harmonics cannot flow due to the isolated neutral points. The matrix $M$ is defined as:

$$
[M]=\frac{1}{3}\left[\begin{array}{cccccc}
2 & -1 & -1 & 0 & 0 & 0 \\
-1 & 2 & -1 & 0 & 0 & 0 \\
-1 & -1 & 2 & 0 & 0 & 0 \\
0 & 0 & 0 & 2 & -1 & -1 \\
0 & 0 & 0 & -1 & 2 & -1 \\
0 & 0 & 0 & -1 & -1 & 2
\end{array}\right]
$$




$$
v_{s}^{\alpha \beta}=V_{d c} \cdot T_{v s d} \cdot M \cdot S^{T}
$$

From the switching state vector represented in (3) all the $64 \mathrm{VVs}$ are obtained. These VVs are classified into two categories: active VVs (60 of them) and null VVs (4 of them). Out of those 60 active VVs, 12 are redundant, hence there are 48 effective active VVs. The active VVs are grouped according to the ascending order of their lengths $\left\{L_{1}, L_{2}, L_{3}, L_{4}\right\}$. Therefore, VVs of the group $L_{1}$ are the shortest and those from $L_{4}$ are the longest. Figure 2 shows the active space VVs in the $\alpha-\beta$ and $x-y$ subspaces.

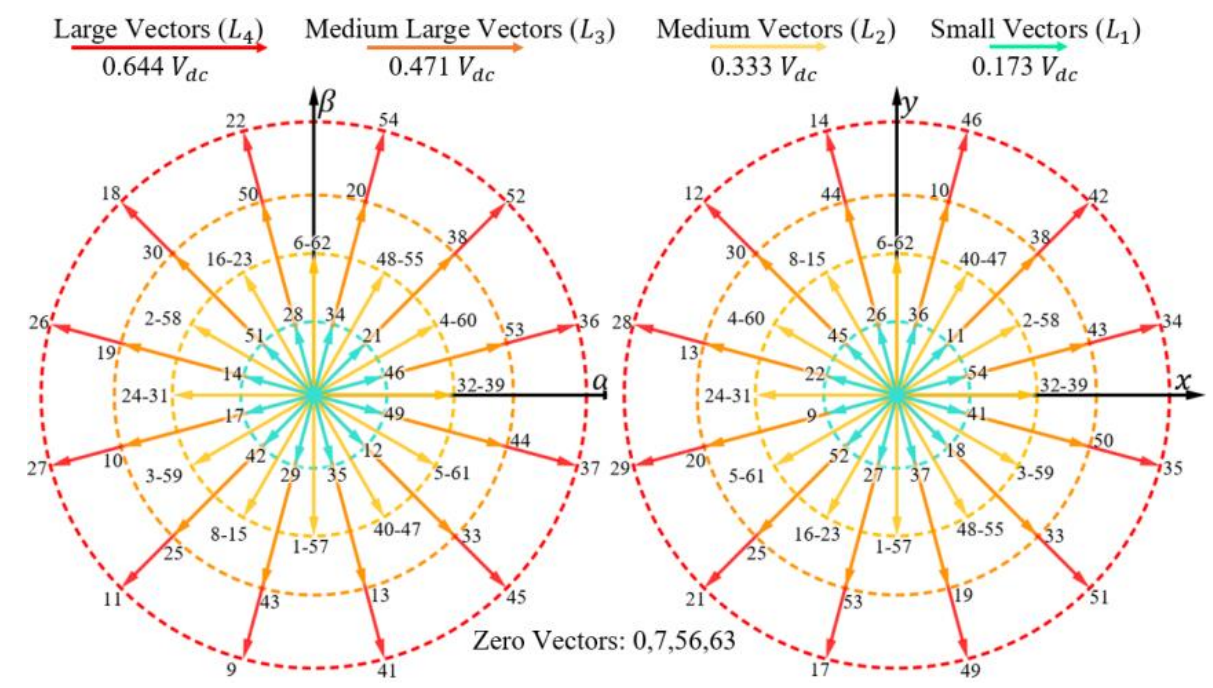

Figure 2. VVs in $\alpha-\beta$ and $x-y$ subspaces.

\subsection{Asymmetrical Six-Phase Induction Machine}

Taking into account that the electromechanical energy conversion involves only quantities in the $\alpha-\beta$ subspace, the Park's transformation in (4) is performed, and $d$ and $q$ components are obtained, respectively, serving at the control stage:

$$
T_{\text {rot }}=\left[\begin{array}{cc}
\cos \theta & \sin \theta \\
-\sin \theta & \cos \theta
\end{array}\right]
$$

where $\theta$ denotes the angle of the rotating reference $d$-axis with respect to $\alpha$-axis.

Using standard assumptions [31], the model of the machine can be transformed into VSD variables, by employing (3)-(4):

$$
\left\{\begin{array}{l}
v_{d s}=R_{s} i_{d s}+\frac{d}{d t} \varphi_{d s}-\omega_{s} \varphi_{q s} \\
v_{q s}=R_{s} i_{q s}+\frac{d}{d t} \varphi_{q s}+\omega_{s} \varphi_{d s} \\
v_{x s}=R_{s} i_{x s}+\frac{d}{d t} \varphi_{x s} \\
v_{y s}=R_{s} i_{y s}+\frac{d}{d t} \varphi_{y s} \\
0=R_{r} i_{d r}+\frac{d}{d t} \varphi_{d r}-\left(\omega_{s}-\omega_{r}\right) \varphi_{q r} \\
0=R_{r} i_{q r}+\frac{d}{d t} \varphi_{q r}+\left(\omega_{s}-\omega_{r}\right) \varphi_{d r}
\end{array}\right.
$$

The stator and rotor flux components can be expressed as:

$$
\left\{\begin{array}{l}
\varphi_{d s}=L_{l s} i_{d s}+L_{m}\left(i_{d s}+i_{d r}\right) \\
\varphi_{q s}=L_{l s} i_{q s}+L_{m}\left(i_{q s}+i_{q r}\right) \\
\varphi_{x s}=L_{l s} i_{x s} \\
\varphi_{y s}=L_{l s} i_{y s} \\
\varphi_{d r}=L_{l r} i_{d r}+L_{m}\left(i_{d s}+i_{d r}\right) \\
\varphi_{q r}=L_{l r} i_{q r}+L_{m}\left(i_{q s}+i_{q r}\right)
\end{array}\right.
$$


where $\omega_{s}$ and $\omega_{r}$ define the reference $d$-axis and rotor electrical angular speed, respectively, $\left\{v_{d s}, v_{q s}, v_{x s}, v_{y s}\right\}$ represent the voltages from the stator, $\left\{\varphi_{d s}, \varphi_{q s}, \varphi_{x s}, \varphi_{y s}\right\}$ and $\left\{\varphi_{d r}, \varphi_{q r}\right\}$ correspond to the flux from the stator and rotor, respectively. Furthermore, $\left\{i_{d s}, i_{q s}, i_{x s}, i_{y s}, i_{d r}, i_{q r}\right\}$ are the currents from stator and rotor, $\left\{R_{s}, R_{r}\right\}$ are the resistances of the stator and rotor, $\left\{L_{l s}, L_{l r}\right\}$ are the phase leakage inductances of stator and rotor, and $L_{m}$ is the mutual inductance between them. Finally, the mechanical equation of the ASIMD can be defined using the following equation:

$$
\begin{gathered}
T_{e}=p\left(\frac{L_{m}}{L_{m}+L_{l r}}\right)\left[i_{q s} \varphi_{d r}-i_{d s} \varphi_{q r}\right] \\
J_{i} \frac{d}{d t} \omega_{m}+B_{i} \omega_{m}=T_{e}-T_{L}
\end{gathered}
$$

being $B_{i}$ the friction coefficient, $J_{i}$ the inertia coefficient, $T_{e}$ defines the electromagnetic torque, $T_{L}$ the load torque, $p$ is the number of pairs of poles, and $\omega_{m}$ the rotor mechanical speed, which can be related to the rotor electrical angular speed using the expression:

$$
\omega_{r}=p \omega_{m}
$$

\section{Classic MPCC}

The classical MPCC can be described as an advanced control strategy that depends on the mathematical model of the machine, to predict the future behavior of the motor currents within a finite prediction horizon, in order to achieve the ideal behavior of the system at the end. The mathematical model of the ASIMD must be in a discrete form so it can be applied to the MPCC. The Classical MPCC evaluates all available switching states of the VSI (shown in Figure 2), every sampling time, and consequently, this implies a high computational burden. Typically, multiphase MPCC includes an outer speed loop with a PI controller, which provides the q-current through the speed loop reference, whereas the $\mathrm{d}$-current reference is assumed to be constant and proportional to the rated magnetic flux. With the model Equations (5)-(6) and with the necessary simplifications in [32] the following voltage equations obtained as:

$$
\left\{\begin{array}{l}
v_{d s}=R_{s} i_{d s}+L_{l s} \frac{d}{d t} i_{d s}-\omega_{s}\left[L_{l s} i_{q s}+T_{r} \varphi_{r} \omega_{s l}\right] \\
v_{q s}=R_{s} i_{q s}+L_{l s} \frac{d}{d t} i_{q s}+\omega_{s}\left[L_{l s} i_{d s}+\varphi_{r}\right] \\
v_{x s}=R_{s} i_{x s}+L_{l s} \frac{d}{d t} i_{x s} \\
v_{y s}=R_{s} i_{y s}+L_{l s} \frac{d}{d t} i_{y s}
\end{array}\right.
$$

where $T_{r}=\frac{L_{l r}}{R_{r}}$, which denotes the rotor time constant, $\varphi_{r}$ is the reference flux from $d$-axis and $\omega_{s l}$ is the slip speed of the motor, that can be estimated by $\omega_{s l}=\omega_{s}-\omega_{r}$.

The predicted currents for the instant $k+1$ are obtained from the previous voltage equations of the model. Using the standard Euler approximation, those equations are given by:

$$
\left\{\begin{array}{l}
i_{d s}^{k+1}=\left(1-\frac{T_{s} R_{s}}{L_{l s}}\right) i_{d s}^{k}+\frac{T_{s}}{L_{l s}} \omega_{s}^{k}\left(L_{l s} i_{q s}^{k}+T_{r} \varphi_{r} \omega_{s l}^{k}\right)+\frac{T_{s}}{L_{l s}} v_{d s}^{k} \\
i_{q s}^{k+1}=\left(1-\frac{T_{s} R_{s}}{L_{l s}}\right) i_{q s}^{k}-\frac{T_{s}}{L_{l s}} \omega_{s}^{k}\left(L_{l s} i_{d s}^{k}+\varphi_{r}\right)+\frac{T_{s}}{L_{l s}} v_{q s}^{k} \\
i_{x s}^{k+1}=\left(1-\frac{T_{s} R_{s}}{L_{l s}}\right) i_{x s}^{k}+\frac{T_{s}}{L_{l s}} v_{x s}^{k} \\
i_{y s}^{k+1}=\left(1-\frac{T_{s} R_{s}}{L_{l s}}\right) i_{y s}^{k}+\frac{T_{s}}{L_{l s}} v_{y s}^{k}
\end{array}\right.
$$

where $T_{s}$ is the sampling time, $\left\{i_{d s}^{k}, i_{q s}^{k}, i_{x s}^{k}, i_{y s}^{k}\right\}$ are the measured currents at the instant $k$, and $\left\{v_{d s}^{k}, v_{q s}^{k}, v_{x s}^{k}, v_{y s}^{k}\right\}$ are the voltages reconstructed from the optimal VV applied to the VSI at the instant $k$.

It is worth mentioning that in practical implementation, a large amount of calculations is required, introducing a considerable time delay in the actuation [33]. This delay may 
deteriorate the performance of the system, if not considered in the design of the controller. Accordingly, Equation (11) of the predicted current at the instant $k+1$ was extended to predicted current at the instant $k+2$ (12). The stator field speed and the slip speed are assumed to be constant over several control periods since the mechanical time of the motor is much greater than the electrical time constant. Therefore, $\omega_{s}^{k+1} \approx \omega_{s}^{k}$ and $\omega_{s l}^{k+1} \approx \omega_{s l}^{k}$ are expressed. The predicted currents in the instant $k+2$ can be written as:

$$
\left\{\begin{array}{l}
i_{d s}^{k+2}=\left(1-\frac{T_{s} R_{s}}{L_{l s}}\right) i_{d s}^{k+1}+\frac{T_{s}}{L_{l s}} \omega_{s}^{k}\left(L_{l s} i_{q s}^{k+1}+T_{r} \varphi_{r} \omega_{s l}^{k}\right)+\frac{T_{s}}{L_{l s}} v_{d s}^{k+1} \\
i_{q s}^{k+2}=\left(1-\frac{T_{s} R_{s}}{L_{l s}}\right) i_{q s}^{k+1}-\frac{T_{s}}{L_{l s}} \omega_{s}^{k}\left(L_{l s} i_{d s}^{k+1}+\varphi_{r}\right)+\frac{T_{s}}{L_{l s}} v_{q s}^{k+1} \\
i_{x s}^{k+2}=\left(1-\frac{T_{s} R_{s}}{L_{l s}}\right) i_{x s}^{k+1}+\frac{T_{s}}{L_{l s}} v_{x s}^{k+1} \\
i_{y s}^{k+2}=\left(1-\frac{T_{s} R_{s}}{L_{l s}}\right) i_{y s}^{k+1}+\frac{T_{s}}{L_{l s}} v_{y s}^{k+1}
\end{array}\right.
$$

where $\left\{v_{d s}^{k+1}, v_{q s}^{k+1}, v_{x s}^{k+1}, v_{y s}^{k+1}\right\}$ are reconstructed voltages from all the possible VVs of the ASIMD.

A minimization procedure is then achieved by selecting the VV that minimizes a predefined cost function. This cost function lists errors in each switching state obtained between the reference and the predicted current two-steps ahead, and then applies the corresponding optimal VV to the smallest error, which is applied to the machine during the next sampling period. The cost function can be defined as:

$$
g=\left(i_{d s}^{*}-i_{d s}^{k+2}\right)^{2}+\left(i_{q s}^{*}-i_{q s}^{k+2}\right)^{2}+\lambda\left[\left(i_{x s}^{*}-i_{x s}^{k+2}\right)^{2}+\left(i_{y s}^{*}-i_{y s}^{k+2}\right)^{2}\right]
$$

where $\left\{i_{d s}^{*}, i_{g s}^{*}, i_{x s}^{*}, i_{y s}^{*}\right\}$ are the stator reference currents and $\lambda$ is the weighting factor that can be defined according to importance of both currents [34].

It is also important to emphasize that all the generated VVs are used for the prediction of the currents. Therefore, in each sampling time, $49 \mathrm{VVs}$ are needed for the evaluation in (13) in the case of ASIMD. Due to the hardware limitation and according to the literature, only 13 candidates are used for prediction and evaluation (12 large VVs and 1 null VV). A simplified scheme of the implemented classic MPCC is shown in Figure 3.

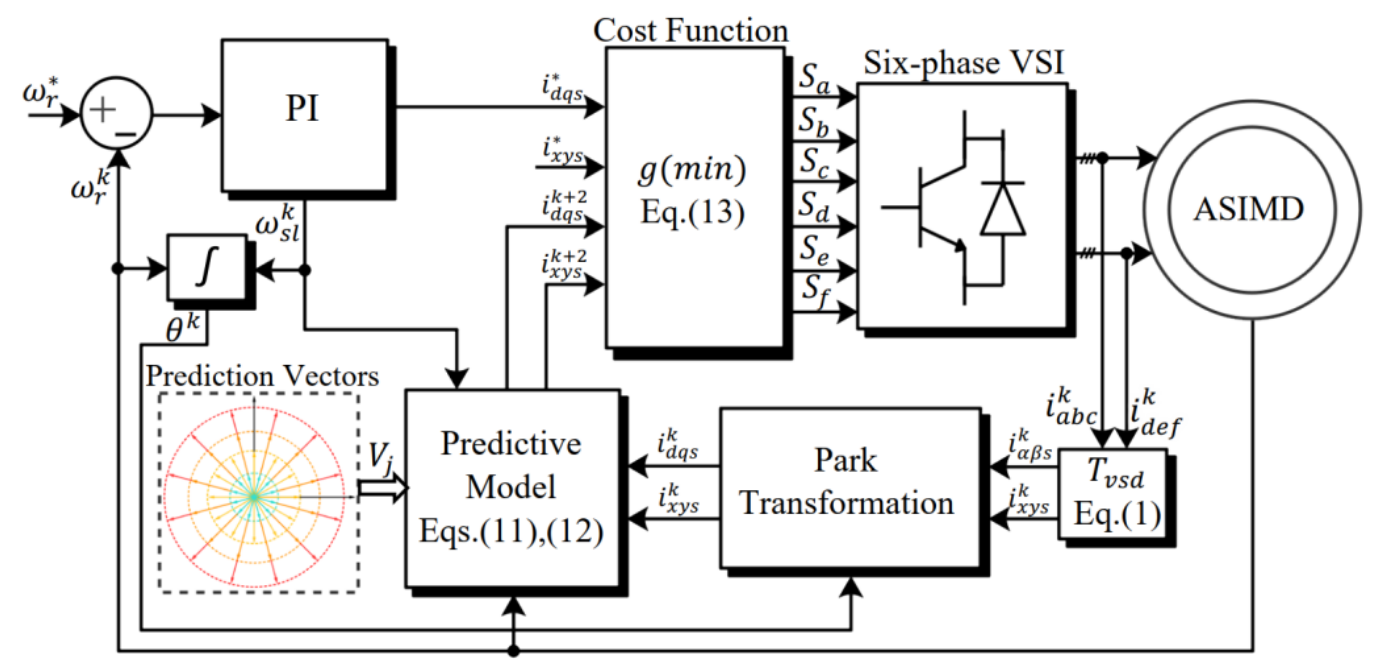

Figure 3. Classic predictive control of the ASIMD.

\section{Proposed DB-MPCC}

\subsection{DB Principle}

The proposed DB-MPCC algorithm obtains an RVV, based on DB. The stator currents are predicted from the mathematical model of the machine, which will select a region 
depending on the position of the RVV. In this method, only the subspace relative to the electromechanical torque is considered, that is, the $d-q$ plane. By using the discrete version of (10) the references voltage equations at instant $k+1$ can be obtained, as expressed in the following:

$$
\left\{\begin{array}{l}
v_{d s}^{*}=R_{s} i_{d s}^{k+1}+L_{l s}\left(\frac{i_{d s}^{k+2}-i_{d s}^{k+1}}{T_{s}}\right)-\omega_{s}^{k+1}\left[L_{l s} k_{q s}^{k+1}+T_{r} \varphi_{r} \omega_{s l}^{k+1}\right] \\
v_{q s}^{*}=R_{s} i_{q s}^{k+1}+L_{l s}\left(\frac{i_{q s}^{k+2}-i_{q s}^{k+1}}{T_{s}}\right)+\omega_{s}^{k+1}\left[L_{l s} k_{d s}^{k+1}+\varphi_{r}\right]
\end{array}\right.
$$

According to the DB-MPCC, the currents at the instant $k+2$ in (14) can be replaced with the corresponding reference currents in order to predict the reference voltages. Thus, the predict reference voltages in $d-q$ subspace can be predicted as:

$$
\left\{\begin{array}{l}
v_{d s}^{*}=R_{s} i_{d s}^{k+1}+L_{l s}\left(\frac{i_{d s}^{*}-i_{d s}^{k+1}}{T_{s}}\right)-\omega_{s}^{k}\left[L_{l s} i_{q s}^{k+1}+T_{r} \varphi_{r} \omega_{s l}^{k}\right] \\
v_{q s}^{*}=R_{s} i_{q s}^{k+1}+L_{l s}\left(\frac{i_{q s}^{*}-i_{q s}^{k+1}}{T_{s}}\right)+\omega_{s}^{k}\left[L_{l s} i_{d s}^{k+1}+\varphi_{r}\right]
\end{array}\right.
$$

where $\left\{v_{d s}^{*}, v_{q s}^{*}\right\}$ are the predicted reference voltages and $\left\{i_{d s}^{*}, i_{q s}^{*}\right\}$ are the reference currents.

To implement the proposed method, it is required to have the voltage in the stationary frame, to obtain its position afterwards. The following expression can transform predicted reference voltages expressions from the rotating frame to the stationary frame:

$$
\left[\begin{array}{c}
v_{\alpha s}^{*} \\
v_{\beta s}^{*}
\end{array}\right]=\left[\begin{array}{cc}
\cos \theta & -\sin \theta \\
\sin \theta & \cos \theta
\end{array}\right] \cdot\left[\begin{array}{c}
v_{d s}^{*} \\
v_{q s}^{*}
\end{array}\right]
$$

where $v_{\alpha s}^{*}, v_{\beta s}^{*}$ are predicted reference voltages in the stationary reference frame. Finally, in order to obtain the position of the RVV from the $\mathrm{DB},(17)$ is expressed as:

$$
\theta_{D B}^{*}=\tan ^{-1}\left(\frac{v_{\beta s}^{*}}{v_{\alpha s}^{*}}\right)
$$

A simplified scheme of the proposed DB-MPCC is shown in Figure 4.

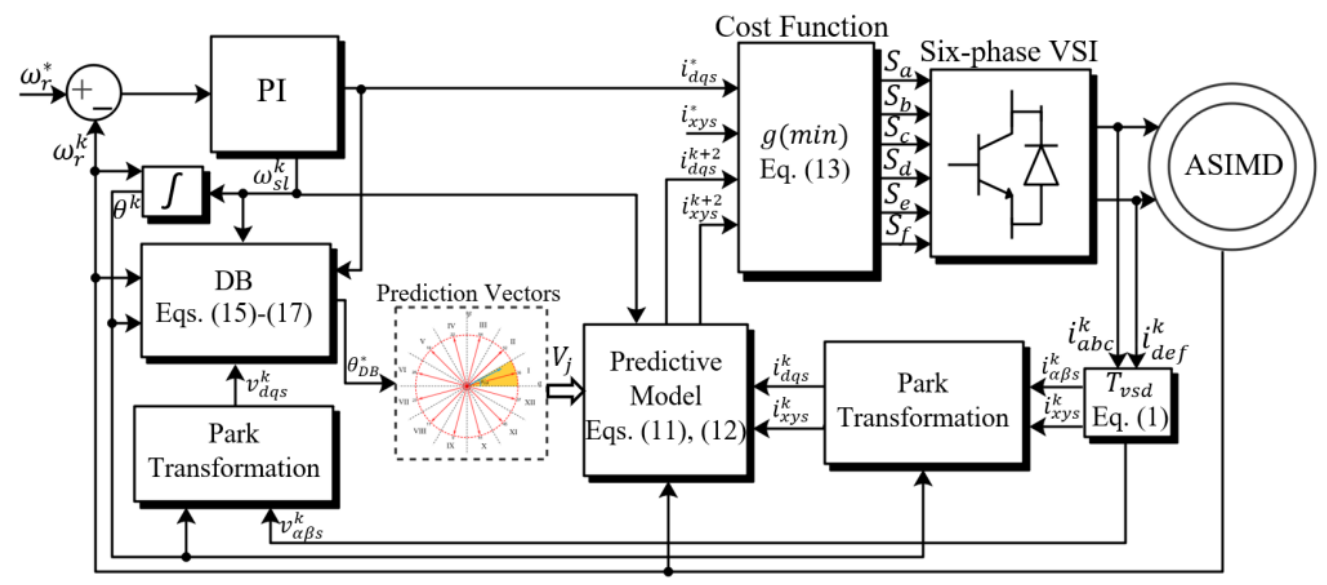

Figure 4. Proposed DB-MPCC control of the ASIMD.

\subsection{VVs Selection from $D B$}

In the proposed DB-MPCC method there is only one possibility to determine the feasible VVs. The $\alpha-\beta$ subspace is divided into 12 equal sections with a range of 30 degrees, as shown in Table 1. In each region there is one distinct large VV. In order to avoid poor control in the region extremities and to achieve a good precision, the two closest large 
VVs are included in the cost function. In addition, one null VV is also added in each case to further improve the control performance. So, for each sampling time, the proposed DB-MPCC has four predicted VVs, choosing one among them, to be applied to the power converter during the next sampling time. The proposed method only employs large VVs, since these VVs minimize $x-y$ currents. The large VVs on $\alpha-\beta$ subspace correspond to the small VVs on $x-y$ subspace. When the secondary current components (typically entitled $x-y$ in the literature) are better regulated, it leads to less system losses and better power quality.

Table 1. Regions of the $\alpha-\beta$ subspace and selection of the feasible VVs.

\begin{tabular}{cc}
\hline \multicolumn{1}{c}{ Regions } & Selection of the Corresponding Set of VVs \\
\hline $\mathrm{I} \rightarrow 0^{\circ} \leq \theta_{D B}^{*}<30^{\circ}$ & $\mathrm{I}=\left[V_{0}, V_{36}, V_{37}, V_{52}\right]$ \\
$\mathrm{II} \rightarrow 30^{\circ} \leq \theta_{D B}^{*}<60^{\circ}$ & $\mathrm{II}=\left[V_{0}, V_{36}, V_{52}, V_{54}\right]$ \\
$\mathrm{III} \rightarrow 60^{\circ} \leq \theta_{D B}^{*}<90^{\circ}$ & $\mathrm{III}=\left[V_{0}, V_{22}, V_{52}, V_{54}\right]$ \\
$\mathrm{IV} \rightarrow 90^{\circ} \leq \theta_{D B}^{*}<120^{\circ}$ & $\mathrm{IV}=\left[V_{0}, V_{18}, V_{22}, V_{54}\right]$ \\
$\mathrm{V} \rightarrow 120^{\circ} \leq \theta_{D B}^{*}<150^{\circ}$ & $\mathrm{V}=\left[V_{0}, V_{18}, V_{22}, V_{26}\right]$ \\
$\mathrm{VI} \rightarrow 150^{\circ} \leq \theta_{D B}^{*}<180^{\circ}$ & $\mathrm{VI}=\left[V_{0}, V_{18}, V_{26}, V_{27}\right]$ \\
$\mathrm{VII} \rightarrow 180^{\circ} \leq \theta_{D B}^{*}<210^{\circ}$ & $\mathrm{VII}=\left[V_{0}, V_{11}, V_{26}, V_{27}\right]$ \\
$\mathrm{VIII} \rightarrow 210^{\circ} \leq \theta_{D B}^{*}<240^{\circ}$ & $\mathrm{VIII}=\left[V_{0}, V_{9}, V_{11}, V_{27}\right]$ \\
$\mathrm{IX} \rightarrow 240^{\circ} \leq \theta_{D B}^{*}<270^{\circ}$ & $\mathrm{IX}=\left[V_{0}, V_{9}, V_{11}, V_{41}\right]$ \\
$\mathrm{X} \rightarrow 270^{\circ} \leq \theta_{D B}^{*}<300^{\circ}$ & $\mathrm{X}=\left[V_{0}, V_{9}, V_{41}, V_{45}\right]$ \\
$\mathrm{XI} \rightarrow 300^{\circ} \leq \theta_{D B}^{*}<330^{\circ}$ & $\mathrm{XI}=\left[V_{0}, V_{37}, V_{41}, V_{45}\right]$ \\
$\mathrm{XII} \rightarrow 330^{\circ} \leq \theta_{D B}^{*}<360^{\circ}$ & $\mathrm{XII}=\left[V_{0}, V_{36}, V_{37}, V_{45}\right]$ \\
\hline
\end{tabular}

Suppose that the RVV gives the position of $27^{\circ}$ in $\alpha-\beta$ subspace, as show in Figure 5. Given the position of the RVV, the region is selected and the candidate VVs will be chosen according to Table 1. In Figure 5 it can be noticed that the region I is selected. For this situation $V_{0}, V_{36}, V_{37}$, and $V_{52}$ are designated and then evaluated in the cost Function (13). Similar to the classical MPCC, the optimal VV, corresponding to the smallest error, is applied to the power converter during in the next sampling period.

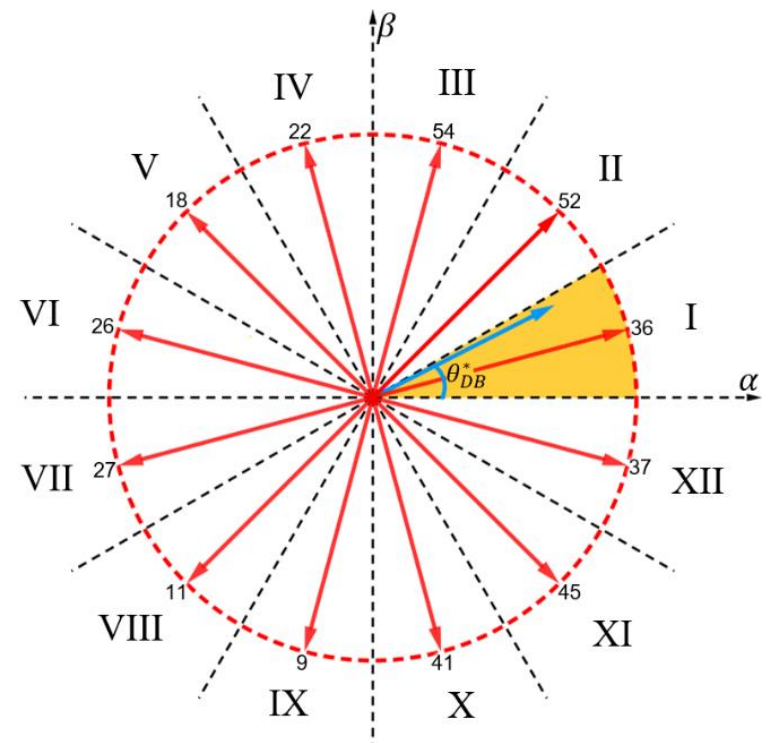

Figure 5. Representation of the predicted reference voltage vector from the deadbeat control and the divided regions of the $\alpha-\beta$ subspace.

For each sampling time, the proposed DB-MPCC has four predicted VVs, choosing one among them to be applied to the power converter during the next sampling time. So, it was possible to register a reduction of VVs used by the MPCC, reducing the number of $13 \mathrm{VVs}$ of the classic MPCC to $4 \mathrm{VVs}$, which corresponds to a smaller number of iterations 
and, consequently, a reduction in the computational effort, enhancing the current and torque quality.

\section{Experimental Results and Discussion}

This section compares the performance of conventional MPCC against the proposed DB-MPCC, using the experimental rig depicted in Figure 6. It consists of a WEG motor, model W21 Multimounting IE1, in the configuration of an ASIMD with two isolated neutrals, supplied by 2L-VSIs from Powerex POW-RPAK VSIs. The VSI control is realized using a digital signal processor (DSP) dSPACE DS1103 digital controller. In the proposed work a 1GHz-dSPACE system based on a DSP was used, which presents interesting features, such as an easy implementation of the code, large available memory (32 MB), and the acquisition of a great amount of data in real-time. The dSPACE reads and acquires data, related to torque, rotation speed and electrical quantities. The following were used: a torque sensor between the shafts of the two motors; an encoder located on the ASIMD shaft; and a sensor panel for reading electrical voltages and currents. The ASIMD parameters are summarized in Table 2.

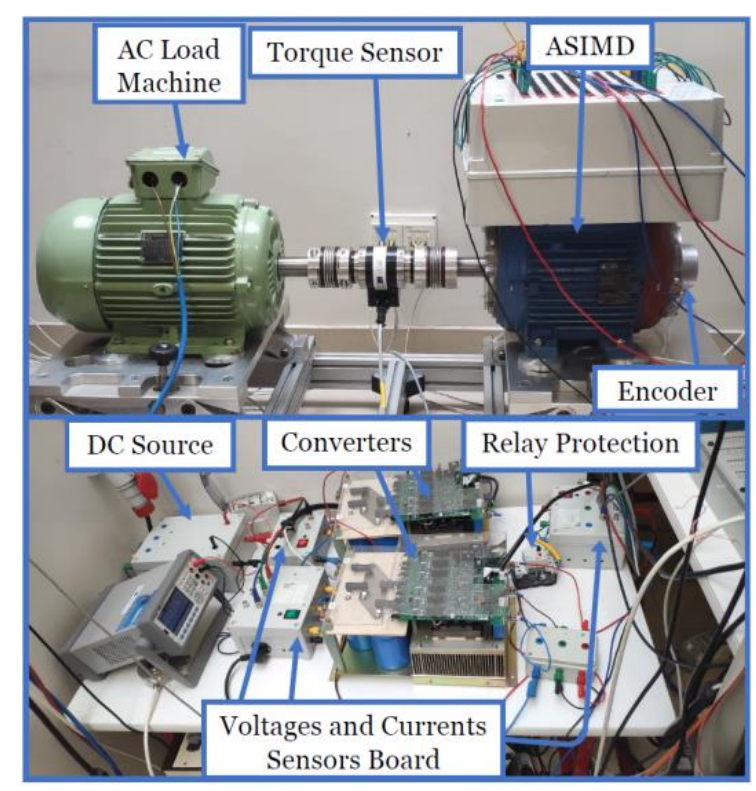

Figure 6. General view of the experimental setup.

Table 2. Parameters of the used ASIMD.

\begin{tabular}{cc}
\hline Parameters & Values \\
\hline DC voltage $V_{d c}(\mathrm{~V})$ & 300 \\
Motor-rated power $(\mathrm{kW})$ & 6 \\
Rated speed $n(\mathrm{rpm})$ & 2930 \\
Rated torque $T_{e}(\mathrm{Nm})$ & 19 \\
Stator resistance $R_{s}(\Omega)$ & 1.87 \\
Stator leakage inductance $L_{l s}(\mathrm{H})$ & $1.48 \times 10^{-2}$ \\
Rotor resistance $R_{r}(\Omega)$ & 0.499 \\
Rotor leakage inductance $L_{l r}(\mathrm{H})$ & $1.48 \times 10^{-2}$ \\
Mutual Inductance $L_{m}(\mathrm{H})$ & 0.199 \\
Rotor inertia $J\left(\mathrm{Kg}-\mathrm{m}^{2}\right)$ & $2.43 \times 10^{-2}$ \\
Coefficient of viscous friction B $(\mathrm{Nm} /(\mathrm{rad} / \mathrm{s}))$ & $9.0 \times 10^{-4}$ \\
No. of pole pairs $(\mathrm{P})$ & 1 \\
\hline
\end{tabular}




\subsection{Computational Effort}

The classical MPCC and the proposed DB-MPCC algorithms are separately implemented under the Matlab/Simulink environment, into the dSPACE DS1103. The computational pre-requisites of a given algorithm are determined by the complexity and demands of the applied programming language. The simplest way to estimate the computational effort of a given algorithm is to implement it in the digital controller to perform all calculations. Considering the procedure described in [35], Table 3 presents the average execution times taken by each algorithm in the dSPACE DS1103 controller.

Table 3. Number of VVs, average execution time, and sampling time of the classical MPCC and DB-MPCC.

\begin{tabular}{cccc}
\hline Type of Control & Numbers of VVs & Execution Time $(\boldsymbol{\mu s})$ & Sampling Time $(\boldsymbol{\mu s})$ \\
\hline Classical MPCC & 13 & 78.82 & 90 \\
DB-MPCC & 4 & 40.39 & 50 \\
\hline
\end{tabular}

The computation time of the classic MPCC with 13 VVs remains significant. On the other hand, in the proposed control, the combination between the DB and MPCC allows the reduction of the candidate VVs from 13 to $4 \mathrm{VVs}$. As a result, the computation time was significantly reduced. The experimental results in Figure 7 and in Table 3, show that one of the most important issues in classical MPCC, which is the excessive computational burden, is significantly reduced from $78.82 \mu$ s to $40.39 \mu$ s (approximately $48.8 \%$ ), using the proposed predictive control scheme, making it very suitable for cheaper microprocessors.
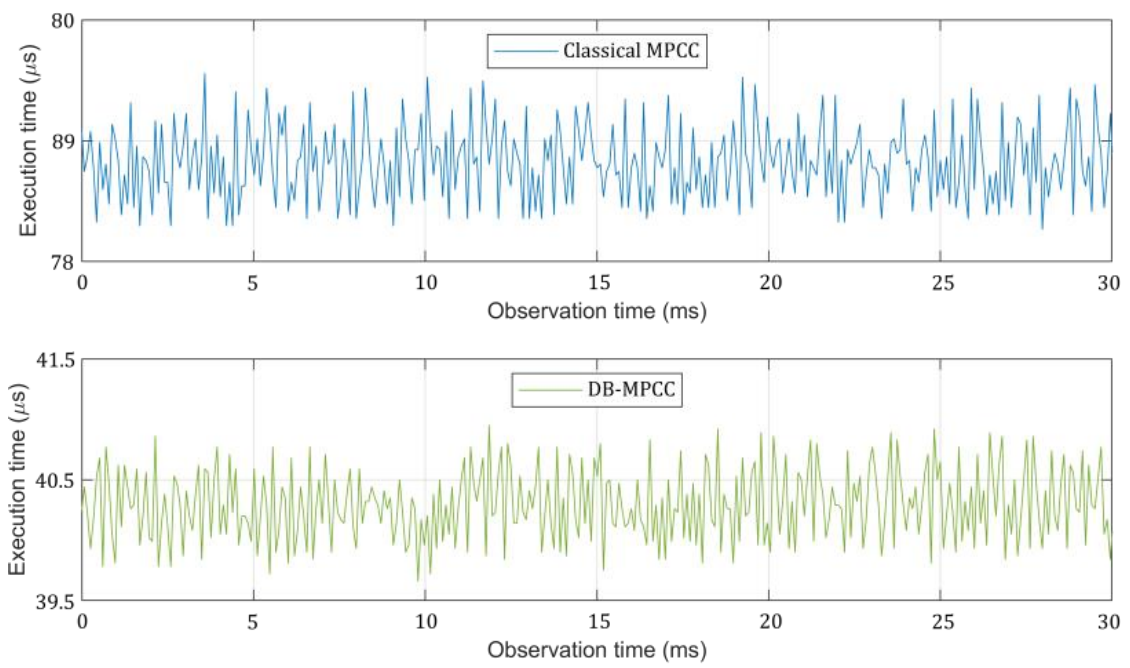

Figure 7. Execution time of the classical MPCC and the proposed DB-MPC algorithms.

Considering the execution time of such algorithm, the sampling time must be greater. The sampling time for the classical MPCC using $13 \mathrm{VVs}$ cannot be much less than $90 \mu \mathrm{s}$ considering the high calculation time. However, using four VVs in the proposed DB-MPCC algorithm, the sampling time can be effectively reduced from $90 \mu$ s to $50 \mu$ s when compared with the classic MPCC algorithm. In this case a reduction from $13 \mathrm{VVs}$ of the classic MPCC to $4 \mathrm{VVs}$ of the proposed control, represents a reduction of about $44.4 \%$ in the sampling time. It's worth mentioning that the execution time of the DB-MPC requires an additional calculation, which was not in the classical MPCC, for the predicted reference stator voltage position and the selection of the VVs according to the sector. However, the calculations are very simple, and therefore, the required extra execution time is much less than the time reduced in the prediction and actuation steps. 


\subsection{Control Performance}

To better evaluate the performance of the different types of control, the total harmonic distortion (THD) is used to quantify the distortion of electrical currents, according to the IEEE standards [36]. The equivalent THD of the 6 phases can be expressed as:

$$
T H D=\sqrt{\frac{T H D_{A}^{2}+T H D_{B}^{2}+T H D_{C}^{2}+T H D_{D}^{2}+T H D_{E}^{2}+T H D_{F}^{2}}{6}} \times 100 \%
$$

Likewise, the total waveform oscillation (TWO) factor is used to quantify the ripple of a given quantity. The TWO is given by:

$$
T W O=\frac{\sqrt{X_{e R M S}^{2}-X_{e D C}^{2}}}{\left|X_{e D C}\right|} \times 100
$$

where $X_{e R M S}$ and $X_{e D C}$ stand for the RMS values and average values of a given quantity, respectively. Extensive experimental tests were conducted to validate the proposed DBMPCC method, feasibility, and control performance. Moreover, the classic MPCC is employed in parallel with the proposed algorithm for comparative purposes. Both controls have been tuned to provide the best possible performance and are tested under the same conditions. To rate the performance of each type of control, the dynamic response of the drive under various operating conditions is considered, as well as the THD of the phase stator currents and the TWO torque values.

The first test (see Figure 8) registers the steady state performance by setting a constant reference speed of $1000 \mathrm{rpm}$, with a constant imposed load torque of $10 \mathrm{~N} \cdot \mathrm{m}$. Firstly, it can be seen that using both control algorithms, the rotor speed follows its reference value.
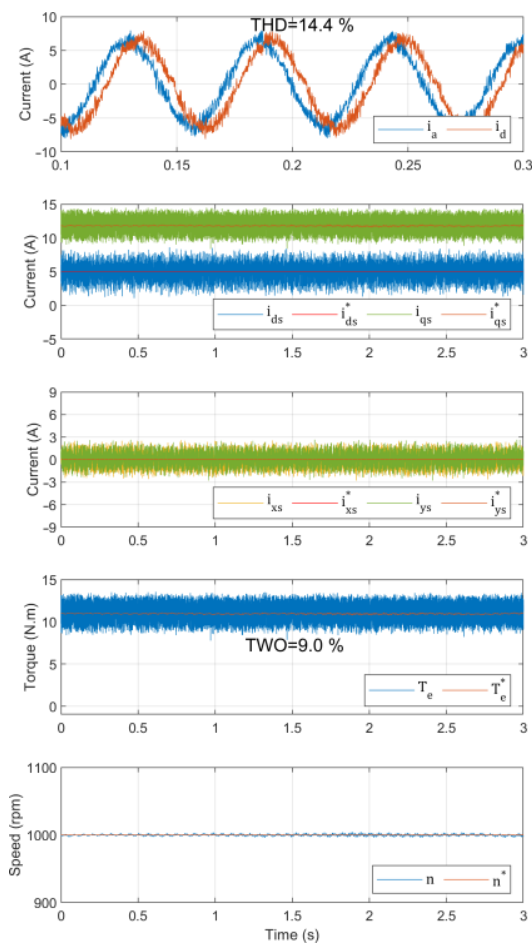

(a)
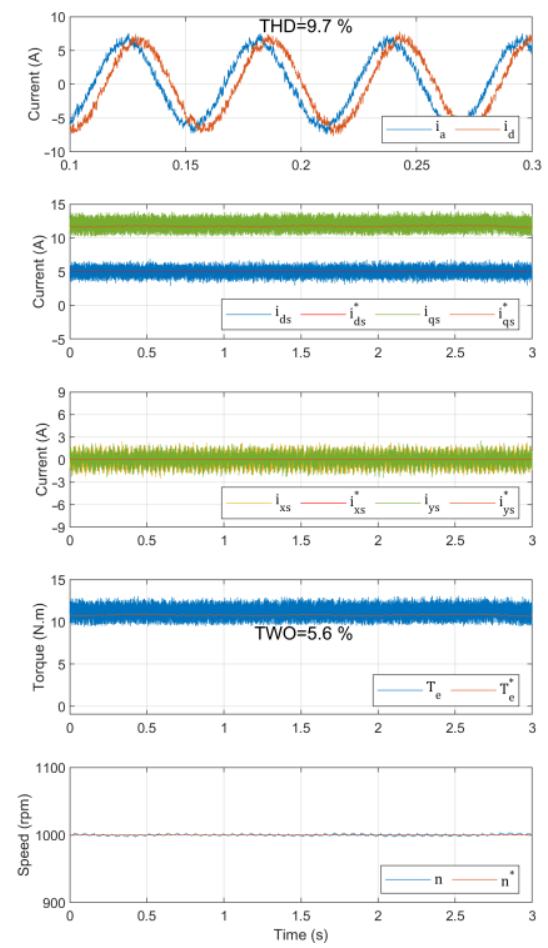

(b)
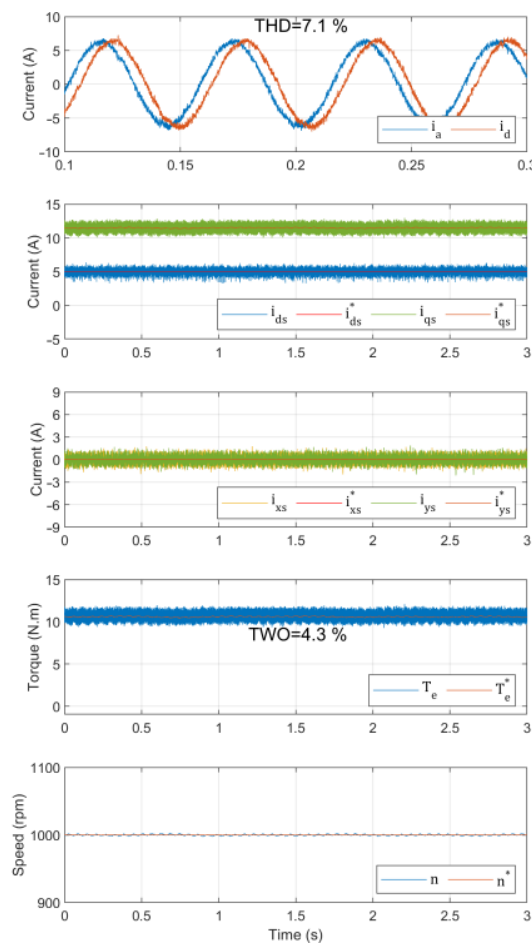

(c)

Figure 8. Experimental results for the first scenario, with a constant speed of $1000 \mathrm{rpm}$ and a constant torque of $10 \mathrm{~N} \cdot \mathrm{m}$, for different types of control: (a) classic MPCC with a sampling time of $90 \mu \mathrm{s}\left(f_{S W}=1.5 \mathrm{kHz}\right)$; (b) proposed DB-MPCC with a sampling time of $90 \mu \mathrm{s}\left(f_{S W}=2.3 \mathrm{kHz}\right)$; and (c) proposed DB-MPCC with a reduced sampling time of $50 \mu \mathrm{s}$ $\left(f_{S W}=3.2 \mathrm{kHz}\right)$. 
In Figure 8a,b both controls present a sampling time of $90 \mu \mathrm{s}$, defined by the classical MPCC for having greater computational effort, and Figure $8 \mathrm{c}$ presents the proposed method with a reduced sampling time of $50 \mu \mathrm{s}$. It can also be noticed in Figure $8 \mathrm{a}, \mathrm{b}$, that the classic MPCC presents a worse regulation of the $d-q$ and the $x-y$ currents compared with the proposed DB-MPCC. The torque and stator phase currents are directly influenced by the $d$ $q$ and the $x-y$ currents, respectively. Accordingly, the classic MPCC shows more prominent stator phase currents and torque oscillations than DB-MPCC for the same sampling time. In respect to THD, it decreases from 14.4\% (classic MPCC) to 9.7\% (DB-MPCC) and TWO reduces from $9.0 \%$ (classic MPCC) to 5.6\% (DB-MPCC). By reducing the sampling time from $90 \mu$ s to $50 \mu$ s (see Figure $8 b, c$ ), there is an improvement in both THD from $9.7 \%$ to $7.1 \%$ and TWO from $5.6 \%$ to $4.3 \%$. Finally, comparing the classic MPCC with the proposed DB-MPCC after reducing the sampling time, a significant improvement of THD around $50.7 \%$ and of TWO around $52.2 \%$ is noticeable.

The second test (see Figure 9) investigates the machine's performance in a condition of a strong torque step from $2 \mathrm{~N} \cdot \mathrm{m}$ to $7 \mathrm{~N} \cdot \mathrm{m}$, for a constant speed of $1000 \mathrm{rpm}$. In this scenario, the fact that the torque value changes, induces an "overshoot" phenomenon in both controls, with a very similar order of magnitude. This phenomenon occurs due to the fact that the motor under study is very heavy and, therefore, the inertia itself does not prevent this phenomenon from occurring. Additionally, it occurs because a strong torque step is applied. The transient state shows a similar rapid dynamic response for both algorithms tested. The rotor speed tracks its reference with high accuracy after a slight descent, due to the applied load torque. Regarding the $d-q$ and $x-y$ currents, it can be noticed in Figure $9 \mathrm{a}, \mathrm{b}$ that the classic MPCC presents larger $d-q$ and $x-y$ currents ripple compared with the DB-MPCC. Besides that, in $d$-q currents plot, it is possible to observe that there is overlaying of both currents $d$ and $q$ in Figure 9 a. As for Figure 9b,c, related to DB-MPCC, there is a clear difference between both currents. The distance that separates currents $d$ from $q$ is directly associated with the control's performance. In this scenario, the classic MPCC shows larger stator phase currents and torque oscillations than DB-MPCC, for the same sampling time of 90 us. Accordingly, the THD and TWO values decreases, leading to an improvement in the overall performance of the machine. By reducing the sampling time from $90 \mu$ s to $50 \mu$ s (see Figure $9 b, c$ ), there is a significant improvement in the two conditions of current THD as in torque TWO. Finally, comparing the classic MPCC with the proposed DB-MPCC after reducing the sampling time, there is an improvement in THD of about $52.0 \%$ for the no-load conditions and about $49.7 \%$ for constant load conditions. In the TWO there is also around 56.3\% improvement for the no-load condition and around $55.0 \%$ improvement for the constant torque condition.

The third test (see Figure 10) investigates the machine's performance in a condition where a speed change from $1000 \mathrm{rpm}$ to $1500 \mathrm{rpm}$ with an acceleration rate of $500 \mathrm{rpm} / \mathrm{s}$, considering a load torque of $2 \mathrm{~N} \cdot \mathrm{m}$. The transient state shows a similar behavior for both algorithms tested. The speed is smoothly tracking its new reference with no significant overshoot. It is worth mentioning that there is a slight imbalance in the sets of motor phases, derived from slight asymmetries in the stator structure. These are more evident under low torque values. Comparing the left (classical MPCC) and middle (DB-MPCC) plots, with the same sampling time of $90 \mu \mathrm{s}$, it is visible that, in the $d-q$ and $x-y$ currents, the classic MPCC introduces more current ripples compared with the DB-MPCC. Moreover, regarding to $d-q$ currents in classic MPCC, it is possible to observe that there is a very small gap between both plots. On the other hand, for Figure 10b,c related to DB-MPCC control with different sample times, there is a clear difference between both plots, especially for a shorter sampling time. Classic MPCC shows larger phase currents ripples and torque oscillations than DB-MPC. Accordingly, using the DB-MPCC the THD and TWO decreases, leading to an improvement in the overall performance of the motor. For a speed of $1500 \mathrm{rpm}$, there is a slightly increase in THD and TWO values, comparatively to a speed of $1000 \mathrm{rpm}$. By reducing the sampling time from $90 \mu \mathrm{s}$, in Figure 10b, to $50 \mu$ s in Figure 10c, under no-load torque conditions at $1500 \mathrm{rpm}$, there is an improvement in THD and TWO values, 
as expected. Finally, comparing the classic MPCC (see Figure 10a) with the proposed DB-MPCC (see Figure 10c), there is an improvement in THD of $50.4 \%$ and TWO of $55.2 \%$, for the condition with no-load torque at $1500 \mathrm{rpm}$.
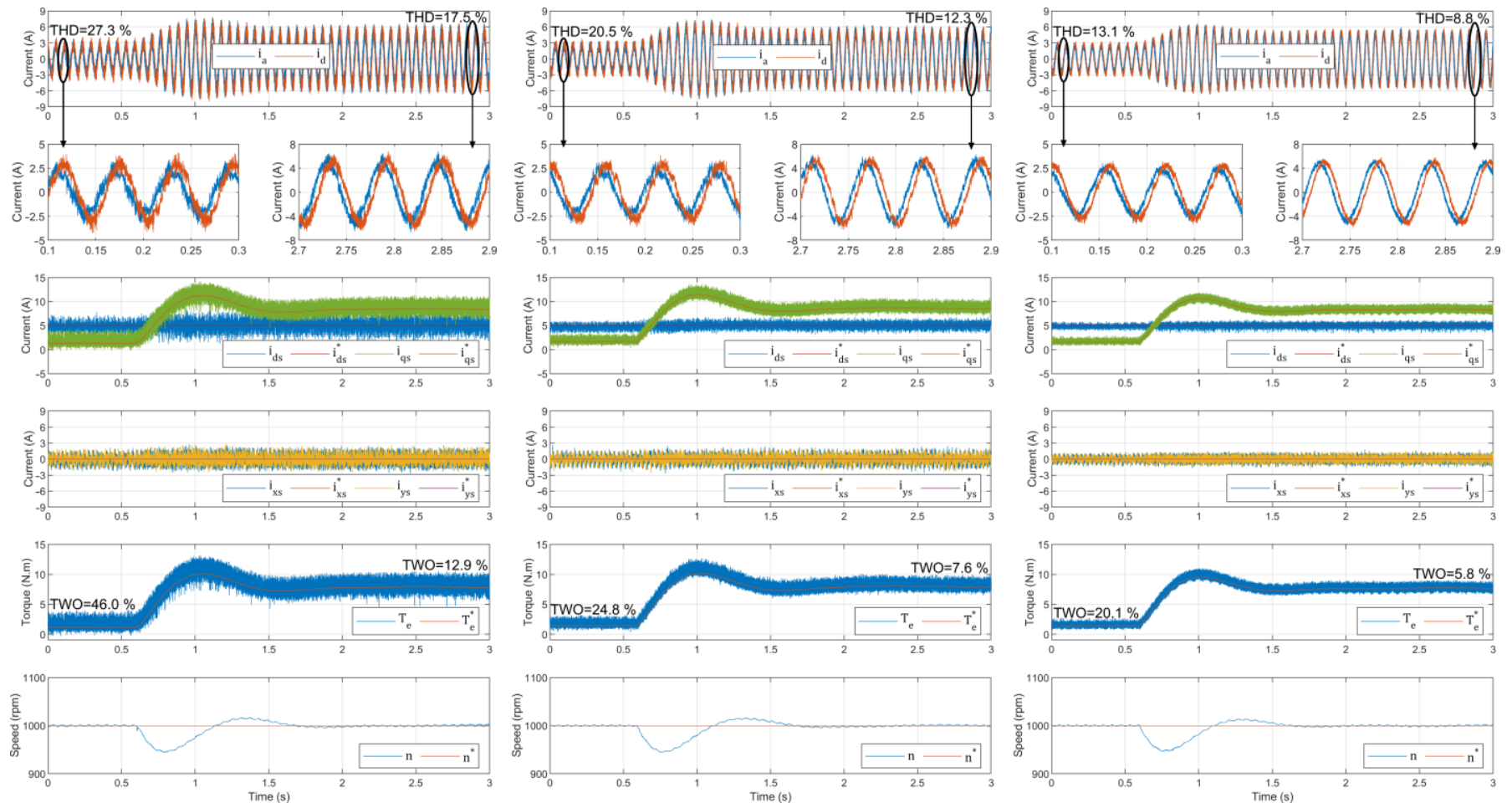

(a)

(b)

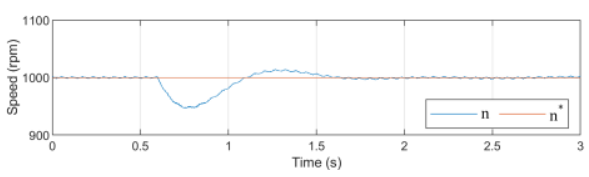

(c)

Figure 9. Experimental results for the second scenario, with a constant speed of $1000 \mathrm{rpm}$ and a torque change from $2 \mathrm{~N} \cdot \mathrm{m}$ to $7 \mathrm{~N} \cdot \mathrm{m}$, for different types of control: (a) classic MPCC with a sampling time of $90 \mu \mathrm{s}\left(2 \mathrm{~N} \cdot \mathrm{m}, f_{S W}=1.6 \mathrm{kHz} ; 7 \mathrm{~N} \cdot \mathrm{m}, f_{S W}=\right.$ $1.6 \mathrm{kHz})$; (b) proposed DB-MPCC with a sampling time of $90 \mu \mathrm{s}\left(2 \mathrm{~N} \cdot \mathrm{m}, f_{S W}=2.4 \mathrm{kHz} ; 7 \mathrm{~N} \cdot \mathrm{m}, f_{S W}=2.2 \mathrm{kHz}\right)$; and (c) proposed DB-MPCC with a reduced sampling time of $50 \mu \mathrm{s}\left(2 \mathrm{~N} \cdot \mathrm{m}, f_{S W}=3.5 \mathrm{kHz} ; 7 \mathrm{~N} \cdot \mathrm{m}, f_{S W}=3.2 \mathrm{kHz}\right)$.

The fourth test (see Figure 11) shows the steady state performance by setting a constant reference speed of $2500 \mathrm{rpm}$, without load torque. It can be observed that using both control schemes, the rotor speed follows its reference value. As previously concluded, the classic MPCC presents a worse regulation of the $d-q$ and the $x-y$ currents than the proposed DBMPCC for the same sampling time. Thus, more torque and stator phase currents ripples are generated. The proposed DB-MPCC outperforms the classical MPCC for the considered operating condition. This is more evident for low sampling time. As in Figures 9 and 10, there is a slight imbalance in the sets of motor phases, due to the slight asymmetries in the stator structure and no-load operating condition.

The average switching frequencies $\left(f_{s w}\right)$ of the considered methods are presented in Figures 8-11. $f_{s w}$ is obtained by counting the total switching jumps of all legs of the 2L-VSI over a fixed period of $0.05 \mathrm{~s}$. Experimental results show that the proposed DBMPCC has slightly higher $f_{s w}$ than the classical MPCC, considering the same sampling time. Indeed, such slight increase in the switching frequency is quite acceptable considering the significant contribution offered by the proposed DB-MPCC. 

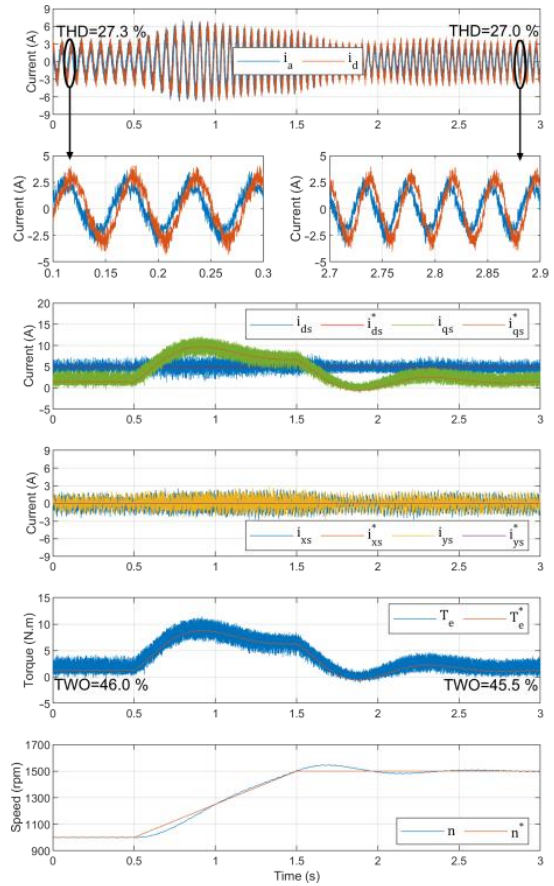

(a)
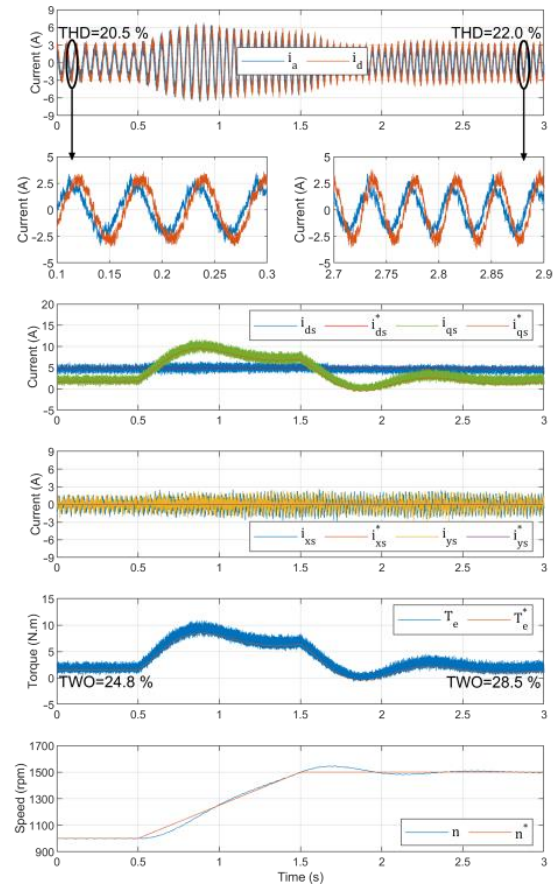

(b)
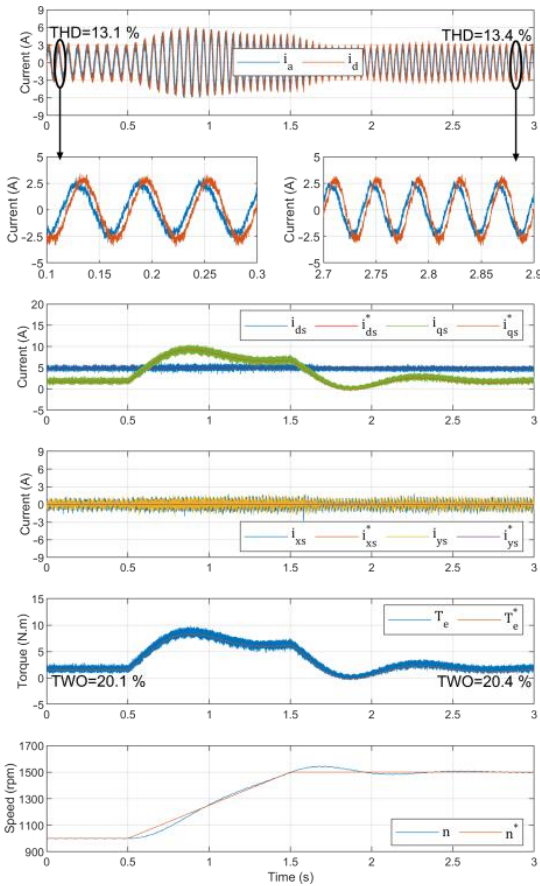

(c)

Figure 10. Experimental results for the third scenario, with a constant torque of $2 \mathrm{~N} \cdot \mathrm{m}$ and a speed change from $1000 \mathrm{rpm}$ to $1500 \mathrm{rpm}$, for different types of control: (a) classic MPCC with a sampling time of $90 \mu \mathrm{s}(1000 \mathrm{rpm}$, $\left.f_{S W}=1.6 \mathrm{kHz} ; 1500 \mathrm{rpm}, f_{S W}=1.4 \mathrm{kHz}\right) ;(\mathbf{b})$ proposed DB-MPCC with a sampling time of $90 \mu \mathrm{s}\left(1000 \mathrm{rpm}, f_{S W}=2.4 \mathrm{kHz}\right.$; $\left.1500 \mathrm{rpm}, f_{S W}=2.1 \mathrm{kHz}\right)$; and $(\mathrm{c})$ proposed DB-MPCC with a reduced sampling time of $50 \mu \mathrm{s}\left(1000 \mathrm{rpm}, f_{S W}=3.5 \mathrm{kHz}\right.$; $1500 \mathrm{rpm}, f_{S W}=3.1 \mathrm{kHz}$ ).
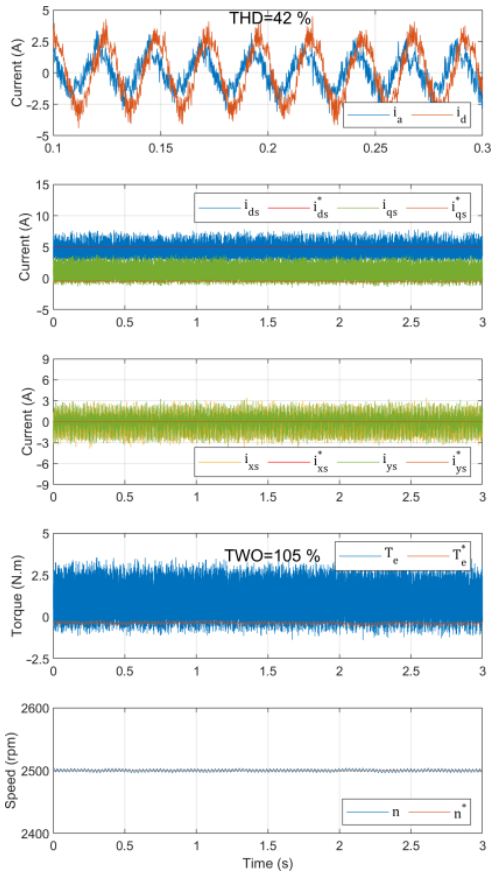

(a)
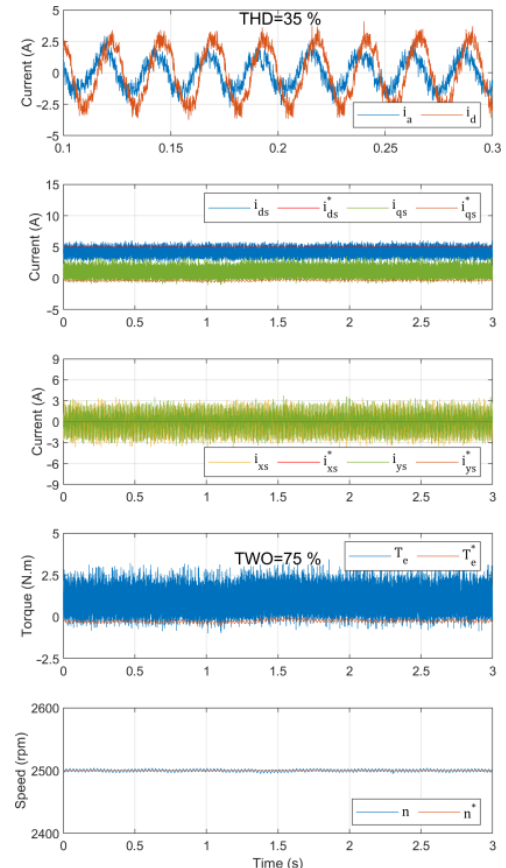

(b)
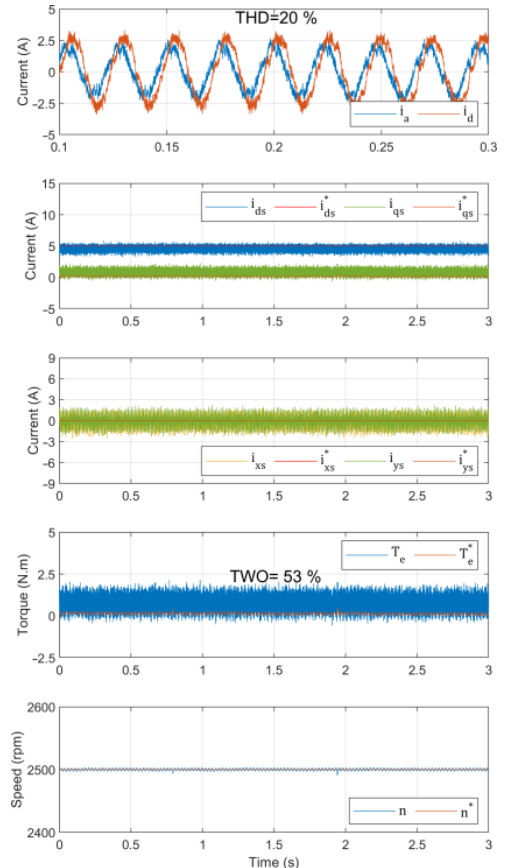

(c)

Figure 11. Experimental results for the fourth scenario, with a constant torque of $0 \mathrm{~N} \cdot \mathrm{m}$ and a constant speed of $2500 \mathrm{rpm}$, for different types of control: (a) classic MPCC with a sampling time of $90 \mu \mathrm{s}\left(2500 \mathrm{rpm}, f_{S W}=1.3 \mathrm{kHz}\right)$; (b) proposed DB-MPCC with a sampling time of $90 \mu \mathrm{s}\left(2500 \mathrm{rpm}, f_{S W}=2.0 \mathrm{kHz}\right)$; and (c) proposed DB-MPCC with a reduced sampling time of $50 \mu \mathrm{s}\left(2500 \mathrm{rpm}, f_{S W}=2.7 \mathrm{kHz}\right)$. 


\section{Conclusions}

This work proposes an enhanced and computationally efficient predictive control of ASIMD, with the prediction and evaluation of only 4 out of 13 possible VVs of the six-phase VSI, to achieve fast dynamic response and favorable steady-state performance.

In the proposed DB-MPCC scheme, two distinct controls are combined: DB and MPCC. By using the DB to estimate the RVV, its position will select a region and, accordingly, the feasible VVs will be evaluated in the MPCC to select the optimal VV. This way, it is possible to reduce the computational time by approximately $48.8 \%$, making it an attractive cost-effective solution. Consequently, with the reduction of sampling time, the DB-MPCC presents much better control performance.

The proposed DB-MPCC overcomes the limitations of the classic MPCC, in terms of being possible to reduce the computational effort and also because it is capable of better regulation of the $x-y$ currents, limiting the stator copper losses and promoting drive efficiency. This enhanced performance is acquired while retaining the capability of MPCC to regulate the speed in both steady and transient states.

The experimental results demonstrate that the DB-MPCC presents a substantial reduction in the THD values of phase current and torque TWO, when compared to the classic MPCC under the same conditions, showing an improvement in the overall performance of the ASIMD.

Author Contributions: Conceptualization, J.S., I.J. and A.J.M.C.; methodology, J.S., I.J. and A.J.M.C.; software, J.S.; validation, J.S. and I.J.; formal analysis, J.S., I.J. and A.J.M.C.; investigation, J.S., I.J. and A.J.M.C.; resources, A.J.M.C.; data curation, J.S. and I.J.; writing-original draft preparation, J.S.; writing-review and editing, I.J. and A.J.M.C.; visualization, J.S., I.J. and A.J.M.C.; supervision, A.J.M.C.; project administration, A.J.M.C.; funding acquisition, A.J.M.C. All authors have read and agreed to the published version of the manuscript.

Funding: This work was supported by the European Regional Development Fund (ERDF) through the Operational Programme for Competitiveness and Internationalization (COMPETE 2020), under Project POCI-01-0145-FEDER-029494, and by National Funds through the FCT - Portuguese Foundation for Science and Technology, under Projects PTDC/EEI-EEE/29494/2017, UIDB/04131/2020, and UIDP/04131/2020.

Institutional Review Board Statement: Not applicable.

Informed Consent Statement: Not applicable.

Data Availability Statement: Not applicable.

Conflicts of Interest: The authors declare no conflict of interest.

\section{References}

1. Levi, E. Advances in Converter Control and Innovative Exploitation of Additional Degrees of Freedom for Multiphase Machines. IEEE Trans. Ind. Electron. 2016, 63, 433-448. [CrossRef]

2. Jung, E.; Yoo, H.; Sul, S.-K.; Choi, H.-S.; Choi, Y.-Y. A Nine-Phase Permanent-Magnet Motor Drive System for an Ultrahigh-Speed Elevator. IEEE Trans. Ind. Appl. 2012, 48, 987-995. [CrossRef]

3. Liu, Z.; Wu, J.; Hao, L. Coordinated and fault-tolerant control of tandem 15-phase induction motors in ship propulsion system. IET Electr. Power Appl. 2018, 12, 91-97. [CrossRef]

4. Yaramasu, V.; Wu, B.; Sen, P.C.; Kouro, S.; Narimani, M. High-power wind energy conversion systems: State-of-the-art and emerging technologies. Proc. IEEE 2015, 103, 740-788. [CrossRef]

5. Cortes, P.; Kaztnierkowski, M.P.; Kennel, R.M.; Quevedo, D.E.; Rodriguez, J. Predictive Control in Power Electronics and Drives. IEEE Trans. Ind. Electron. 2008, 55, 4312-4324. [CrossRef]

6. Mesai-Ahmed, H.; Jlassi, I.; Cardoso, A.J.M.; Bentaallah, A. Model-Free Predictive Current Control of Synchronous Reluctance Motors Based on a Recurrent Neural Network. IEEE Trans. Ind. Electron. 2021. [CrossRef]

7. De Martin, I.D.; Pasqualotto, D.; Tinazzi, F.; Zigliotto, M. Model-Free Predictive Current Control of Synchronous Reluctance Motor Drives for Pump Applications. Machines 2021, 9, 217. [CrossRef]

8. Gonzalez-Prieto, A.; Gonzalez-Prieto, I.; Duran, M.J.; Aciego, J.J.; Salas-Biedma, P. Current Harmonic Mitigation Using a Multi-Vector Solution for MPC in Six-Phase Electric Drives. IEEE Access 2021, 9, 117761-117771. [CrossRef] 
9. Jlassi, I.; Cardoso, A.J.M. Enhanced and Computationally Efficient Model Predictive Flux and Power Control of PMSG Drives for Wind Turbine Applications. IEEE Trans. Ind. Electron. 2021, 68, 6574-6583. [CrossRef]

10. Vazquez, S.; Rodriguez, J.; Rivera, M.; Franquelo, L.G.; Norambuena, M. Model Predictive Control for Power Converters and Drives: Advances and Trends. IEEE Trans. Ind. Electron. 2017, 64, 935-947. [CrossRef]

11. Galuppini, G.; Magni, L.; Raimondo, D.M. Model predictive control of systems with deadzone and saturation. Control. Eng. Pract. 2018, 78, 56-64. [CrossRef]

12. Jlassi, I.; Cardoso, A.J.M. Lookup-Table-Based Model Predictive Torque Control without Weighting Factors for PMSM Drives. In Proceedings of the IECON 2019—45th Annual Conference of the IEEE Industrial Electronics Society, Lisbon, Portugal, 14-17 October 2019; Volume 1, pp. 1165-1170.

13. Guechi, E.-H.; Bouzoualegh, S.; Zennir, Y.; Blažič, S. MPC Control and LQ Optimal Control of A Two-Link Robot Arm: A Comparative Study. Machines 2018, 6, 37. [CrossRef]

14. Jlassi, I.; Cardoso, A.J.M. Model Predictive Current Control of Synchronous Reluctance Motors, Including Saturation and Iron Losses. In Proceedings of the 2018 XIII International Conference on Electrical Machines (ICEM), Alexandroupoli, Greece, 3-6 September 2018; pp. 1598-1603.

15. Kouro, S.; Cortes, P.; Vargas, R.; Ammann, U.; Rodriguez, J. Model Predictive Control—A Simple and Powerful Method to Control Power Converters. IEEE Trans. Ind. Electron. 2008, 56, 1826-1838. [CrossRef]

16. Gmati, B.; Jlassi, I.; El Khil, S.K.; Cardoso, A.J.M. Open-switch fault diagnosis in voltage source inverters of PMSM drives using predictive current errors and fuzzy logic approach. IET Power Electron. 2021, 14, 1059-1072. [CrossRef]

17. Laadjal, K.; Bento, F.; Jlassi, I.; Cardoso, A.J.M. Online Condition Monitoring of Electrolytic Capacitors in DC-DC Interleaved Boost Converters, Adopting a Model-Free Predictive Controller. In Proceedings of the 2021 IEEE 15th International Conference on Compatibility, Power Electronics and Power Engineering (CPE-POWERENG), Florence, Italy, 14-16 July 2021 ; pp. 1-6.

18. Chai, M.; Gorla, N.B.Y.; Panda, S.K. Fault Detection and Localization for Cascaded H-Bridge Multilevel Converter With Model Predictive Control. IEEE Trans. Power Electron. 2020, 35, 10109-10120. [CrossRef]

19. Zhou, D.; Yang, S.; Tang, Y. A Voltage-Based Open-Circuit Fault Detection and Isolation Approach for Modular Multilevel Converters with Model-Predictive Control. IEEE Trans. Power Electron. 2018, 33, 9866-9874. [CrossRef]

20. Jlassi, I.; Cardoso, A.J.M. Open-circuit fault-tolerant operation of permanent magnet synchronous generator drives for wind turbine systems using a computationally efficient model predictive current control. IET Electr. Power Appl. 2021, 15, 837-846. [CrossRef]

21. Jlassi, I.; Cardoso, A.J.M. Fault-Tolerant Back-to-Back Converter for Direct-Drive PMSG Wind Turbines Using Direct Torque and Power Control Techniques. IEEE Trans. Power Electron. 2019, 34, 11215-11227. [CrossRef]

22. Martín, C.; Bermúdez, M.; Barrero, F.; Arahal, M.R.; Kestelyn, X.; Durán, M.J. Sensitivity of predictive controllers to parameter variation in five-phase induction motor drives. Control. Eng. Pract. 2017, 68, 23-31. [CrossRef]

23. Barrero, F.; Arahal, M.R.; Gregor, R.; Toral, S.; Duran, M.J. A Proof of Concept Study of Predictive Current Control for VSI-Driven Asymmetrical Dual Three-Phase AC Machines. IEEE Trans. Ind. Electron. 2009, 56, 1937-1954. [CrossRef]

24. Gonzalez-Prieto, I.; Duran, M.J.; Aciego, J.J.; Martin, C.; Barrero, F. Model Predictive Control of Six-Phase Induction Motor Drives Using Virtual Voltage Vectors. IEEE Trans. Ind. Electron. 2018, 65, 27-37. [CrossRef]

25. Aciego, J.J.; Prieto, I.G.; Duran, M.J. Model Predictive Control of Six-Phase Induction Motor Drives Using Two Virtual Voltage Vectors. IEEE J. Emerg. Sel. Top. Power Electron. 2018, 7, 321-330. [CrossRef]

26. Zhang, Y.; Xu, D.; Liu, J.; Gao, S.; Xu, W. Performance Improvement of Model-Predictive Current Control of Permanent Magnet Synchronous Motor Drives. IEEE Trans. Ind. Appl. 2017, 53, 3683-3695. [CrossRef]

27. Xie, W.; Wang, X.; Wang, F.; Xu, W.; Kennel, R.M.; Gerling, D.; Lorenz, R.D. Finite-Control-Set Model Predictive Torque Control with a Deadbeat Solution for PMSM Drives. IEEE Trans. Ind. Electron. 2015, 62, 5402-5410. [CrossRef]

28. Zhang, X.; Hou, B. Double Vectors Model Predictive Torque Control without Weighting Factor Based on Voltage Tracking Error. IEEE Trans. Power Electron. 2018, 33, 2368-2380. [CrossRef]

29. Luo, Y.; Liu, C. Elimination of Harmonic Currents Using a Reference Voltage Vector Based-Model Predictive Control for a Six-Phase PMSM Motor. IEEE Trans. Power Electron. 2019, 34, 6960-6972. [CrossRef]

30. Luo, Y.; Liu, C. Model Predictive Control for a Six-Phase PMSM Motor with a Reduced-Dimension Cost Function. IEEE Trans. Ind. Electron. 2019, 67, 969-979. [CrossRef]

31. Levi, E. Multiphase Electric Machines for Variable-Speed Applications. IEEE Trans. Ind. Electron. 2008, 55, 1893-1909. [CrossRef]

32. Singh, G.K.; Nam, K.; Lim, S.K. A Simple Indirect Field-Oriented Control Scheme for Multiphase Induction Machine. IEEE Trans. Ind. Electron. 2005, 52, 1177-1184. [CrossRef]

33. Cortes, P.; Rodriguez, J.; Silva, C.; Flores, A. Delay Compensation in Model Predictive Current Control of a Three-Phase Inverter. IEEE Trans. Ind. Electron. 2012, 59, 1323-1325. [CrossRef]

34. Cortes, P.; Kouro, S.; La Rocca, B.; Vargas, R.; Rodriguez, J.; Leon, J.I.; Vazquez, S.; Franquelo, L.G. Guidelines for weighting factors design in Model Predictive Control of power converters and drives. In Proceedings of the IEEE International Confer-ence on Industrial Technology, Churchill, VIC, Australia, 10-13 February 2009; pp. 1-7. [CrossRef] 
35. dSPACE GmbH. Available online: https://www.dspace.com/en/ltd/home/support/kb/faqs/faq023.cfm (accessed on 1 October 2021).

36. IEEE Recommended Practices and Requirements for Harmonic Control in Electrical Power Systems. Available online: https: / /d1wqtxts1xzle7.cloudfront.net/44174443/IEEE519-with-cover-page-v2.pdf?Expires=1637657090\&Signature=Mb- $\mathrm{zH}$ m2QNGFJ1IXS2lqWhZa6qbVEtyAFXrnXtgKdhtS0Cd4HEBaUW8BJn-TV6eibK4FYtdtd8maEVfO616Kjyh1HGzGDVk2lXICvP 2gPKrVm9TNyFjO \{\}D \{ \{N2ik \{\}zJ5jHvy89trfv \{\}MS3s \{\}FcjFFmopGd5xTyu9udcHlMn6-JL6V9nt1ILihxp5 \{\}UTpNbaBQfe7 vyG8OCQSew6YfhgzGD7q1m21XCh8wiXt5MgHyKTushjk8aTe5qy7ohQR5wlob9nQjyFu3KGNGxsRH7sow1eV95WHae9bWi CTicNT4nIobDyrvw3j-xEjV7I0oUGFsS3LgrZ-uSIpNam86v4ca1hw_\&Key-Pair-Id=APKAJLOHF5GGSLRBV4ZA (accessed on 1 October 2021). 